\title{
Manipulación emocional televisiva como instrumento para someter a los pueblos latinoamericanos
}

\author{
Handling emotional TV as a means to subdue the Latin American peoples
}

Lautaro Matías Taibo Rodríguez ${ }^{1}$

1 Licenciado en ciencia Política de la UBA. Miembro de la APDH Argentina. Creador de la Fundación internacional "Jóvenes por el ALBA". Investigador y columnista político. Asesor político en el poder legislativo, investigador de la FLACSO y del CESyT. Correo electrónico: lautarotaibo@hotmail.com

\section{RESUMEN}

La construcción de nuevos polos de poder en el área de medios de comunicación es la herramienta para contribuir a la ruptura de la dominación de los imperios sobre nuestros territorios. Se hace impostergable centrar los ejes de las discusiones contemporáneas en el papel de los medios de comunicación y en la influencia de los mismos a la hora de fortalecer o debilitar el apoyo de la población a diferentes gobiernos populares. Para esto es necesario analizar las principales herramienta que se utilizan en la tan nombrada y aun así poco explorada "Guerra de Cuarta Generación".

En nuestro trabajo hemos interpretado la manipulación emocional ejercida tanto por los noticieros estelares de los medios de comunicación Canal 7 (La tv Pública) y Canal 13 (el Trece) de Argentina, como por los de los canales Globovisión y VTV (Venezolana de Televisión) en la República Bolivariana de Venezuela. Para esto hemos creado una nueva metodología de investigación denominada "Deconstruccionismo Sensorial" la cual tiene como particularidad que, para su aplicación, el investigador debe anular algunos de sus sentidos sensoriales para evitar ser manipulado mientras realiza la investigación. Los resultados obtenidos constituyen ejes centrales para entender en de qué forma operan las armas de manipulación televisivas.
Palabras Claves: Manipulación emocional, Información, Medios Libertarios, Medios Sometedores y Deconstruccionismo Sensorial

\section{ABSTRACT}

The construction of new poles of power in the area of mass media is the tool to contribute to the break of the domination of the empires on our territories. It becomes ineluctable to center the axes of the contemporary discussions on the paper of the mass media and on the influence of the same ones at the moment of strengthening or to debilitate the support of the population to different popular governments. For this it is necessary to analyze principal tool that they use in so renowned and even this way little explored "War of Fourth Generation “.

In our work we have interpreted the emotional manipulation exercised so much by the stellar newscasters of the mass media Channel 7 (The Public TV) and Channel 13 (The Thirteen) of Argentina, since for those of the channels Globovisión and VTV (Venezuelan of Television) in the Bolivarian Republic of Venezuela. For this we have created a new methodology of investigation named "Sensorial Deconstruccionism" which has as particularity that, for his application, the investigator must annul certain sensory senses to avoid to be manipulated while it realizes the investigation. The obtained results constitute backbones to deal in what it forms produce the television weapon of manipulation. 


\section{INTRODUCCIÓN}

La construcción de un Mundo Multipolar es esencial para fortalecer la autodeterminación de los pueblos. Esto, que fue innumerables veces mencionado por el comandante Hugo Chávez, supone la formación de nuevos polos de poder que contribuyan a la ruptura de la dominación de los imperios -principalmente el norteamericano- sobre Latinoamérica. El Proyecto nacional Simón Bolívar de los años 2007-2013 establece que para la "articulación de los nuevos polos de poder geopolíticos (...) se deben definir nuevas formas y mecanismos de integración y relaciones, que logren la construcción de una nueva matriz de poder mundial en el campo (...) mediático (...) y político" (p.91). Asimismo, Chávez (2012) en el reconocido Plan de la Patria del Gobierno Bolivariano para el período 2013-2019 postula que es necesario "conformar un nuevo orden comunicacional del Sur"(p.112). Estas metas obligan necesariamente a centrar uno de los ejes de las discusiones contemporáneas en el papel de los medios de comunicación y en la influencia de los mismos a la hora de fortalecer o debilitar el apoyo de la población a sus diferentes gobiernos.

Analizar la dominación imperialista, principalmente de los Estados Unidos, sobre la región Latinoamericana es crucial en este tema. La misma se ejerce dentro de dos planos diferentes y a la vez complementarios: Uno es la coerción, que es directo, letal, el poder ejercido como castigo a los gobiernos "rojos" de la región. El otro plano es el de la disuasión y manipulación que se ejerce principalmente a través de los medios de comunicación y es sutil, encubierta, enmascarada. Esta arma se utiliza diariamente para difundir la ideología hegemónica imperialista e influenciar a las poblaciones para lograr su sumisión voluntaria. Este último se muestra como opuesto al primero pero, en realidad, es la contracara que lo sustenta; legitima las acciones coercitivas, crea velos para ocultar la realidad o tergiversarla, inventa héroes que deben vencer y villanos que deben ser vencidos.
La liberación de los pueblos latinoamericanos, por lo tanto, debe producirse principalmente en el campo cultural e ideológico; ámbitos a través de los cuales más han logrado someter a los pueblos latinoamericanos. Es por esta misma razón que se produce la denominada "guerra de cuarta generación" entre los medios de comunicación que definiremos como "Medios Sometedores" -por un lado- y los "Medios Libertarios" -por el otro-. Esta batalla tiene relevancia en la actualidad por la velocidad a la que se puede difundir un concepto; una idea, una imagen o un sonido llegando a millones de personas en cualquier parte del globo con solo hacer un click en el "control remoto" que, con las nuevas tecnologías, se ha convertido en algo más; en un mouse, en una grabadora, en un reconocedor de voz y mucho, mucho más.

En la investigación realizada, se hizo eje en dos países de Latinoamérica; la República Bolivariana de Venezuela y la República Argentina. La novedosa metodología utilizada, sin embargo, puede ser aplicada en futuras investigaciones sobre medios de comunicación audiovisuales en otros países de nuestra Abya-Yala. En cuanto al problema de investigación que guió la investigación consistió en la "Utilización de estímulos emocionales con la finalidad de generar grados de conciencia descendentes para crear mayor sometimiento de los televidentes de los noticieros estelares de los canales Globovisión y VTV de la República Bolivariana de Venezuela y Canal 13 y Canal 7 de la República Argentina".

Se decidió seleccionar, como medio de comunicación a investigar, a la televisión debido a que, la misma, ha formado por más de 50 años determinados hábitos y costumbres. Di Guglielmo (2010) considera que esto sucede porque la televisión (...) nos une, nos da una cultura en común, ciertos intereses compartidos. $Y$ ocurre porque hemos visto esas mismas cosas al mismo tiempo. Son vivencias compartidas en tiempo y espacio. (...) La televisión, especialmente 
la de aire, cumple una función integradora en una sociedad" (p.72). Asimismo establece que "la televisión (...) es un hecho cultural irrebatible, un aglutinador de percepciones"(p.125). A esto se añade que, para ver televisión, no se necesita ninguna preparación educativa previa. Esto no sucede, por ejemplo, con internet donde la navegación por la red exige conocimientos más complejos por lo que la accesibilidad a este medio se limita considerablemente. La investigación se centró en los noticieros estelares de los canales que representan tanto las posturas de los gobiernos chavistas y kirchneristas como de los sectores más opositores a los mismos. El Objeto de Estudio de la investigación fue, por lo tanto, los noticieros estelares "La Noticia Emisión estelar", del canal televisión VTV (gubernamental) y "Noticias Globovisión" del canal Globovisión (opositor) de la República Bolivariana de Venezuela mientras que de la República Argentina se interpretarán tanto los noticieros estelares "Visión Siete Central", del Canal 7 (gubernamental) como "Telenoche" del Canal 13 (opositor).

Autores de reconocida trayectoria como Buen Abad Fernando han interpretado a los medios de comunicación, y a la comunicación en general, desde aspectos filosóficos, políticos y semióticos, entre otros, siendo uno de los intelectuales que más escritos ha dedicado al tema. Sus definiciones de "comunicación", "Mass Media" y "Manipulación" marcan una ruptura con las visiones hegemónicas posicionándose como una antítesis frente a estas. Otro escritor importante dentro del área es Romano Vicente quien se constituye como un exponente ineludible por sus aportes en el estudio de la violencia mediática y de discursos realizados por los medios de comunicación hegemónicos.

A esto se asuman las contribuciones, en materia de construcción de una comunicación Nuestroamericana, de Aharonian (2007) en relación a la necesidad de "vernos con nuestros propios ojos" y no desde los ojos de la ideología imperialista capitalista. Es sin embargo imposible dejar de mencionar los aportes de Britto (2012) con sus estudios de la manipulación mediática aplicados al caso del intento de golpe de Estado del 2002 en la República Bolivariana de Venezuela. Finalmente vale la pena mencionar que, la editorial "La Crujía", ha sido una de las que se ha centrado en las investigaciones relacionadas con el estudio mediático haciendo especial énfasis en las maniobras psicológicas. Claro exponente de esto es el libro de los autores Beaudoux, D’Adamo \& Slavinsky (2011) "Propaganda gubernamental; Tácticas e iconografías del poder" - en el cual se indaga en la manipulación, la propaganda y la guerra psicológica (entre otros) llevada a cabo por diferentes gobiernos como por ejemplo los de EEUU, URSS, Israel, Francia, Brasil, Alemania, etcétera.

Otro libro, de la misma editorial, digno de mencionar es el escrito por Di Guglielmo (2010) "La Programación Televisiva en Guerra", que analiza aspectos relacionados con los formatos, el nivel de audiencia, los enlatados, y los negocios que se esconden detrás de los programas televisivos del continente americano formando trascendentales soportes teóricos desde una perspectiva más pragmática y sustentada en la larga trayectoria del autor. Finalmente, los libros de Gergen, Lewis \& Izurieta (2005) "Cambiando la escucha; comunicación presidencial para ciudadanos indiferente" y Apriles (2006) "La publicidad puesta al día" destacan las diferentes formas en las que se deben y no se deben transmitir mensajes políticos. En el contexto de los escritos, análisis, investigaciones y aportes de estos intelectuales, se ha establecido el objetivo general de la investigación como "Interpretar la presencia de estímulos emocionales, tendientes a manipular a los televidentes, en los noticieros estelares "Noticias Globovisión", "La Noticia Emisión Estelar", "Telenoche" y "Visión Siete Central". Se indagó asimismo en la relación entre la tendencia política de un gobierno y el aumento o disminución de la intención de manipulación de los medios de comunicación televisivos sobre la población. 
La información e ideas derivadas de esta investigación son importantes para realizar una guerrilla-comunicacional más efectiva en vistas de la necesidad de defender los procesos revolucionarios y progresistas que se están llevando a cabo. La manipulación como instrumento de desestabilización política fue y es utilizado por medios opositores principalmente en la República Bolivariana de Venezuela durante los gobiernos de Hugo Chávez y actualmente en el Gobierno de Nicolás Maduro. Esta manipulación fue central en los intentos de golpe de estado de Abril de 2002 y 2013 llegando, los medios opositores, a posicionarse como principales pilares de apoyo de ambos intentos antidemocráticos.

Para el trabajo investigativo se tomaron en cuenta algunas definiciones que son centrales dentro de la temática de la manipulación en los medios de comunicación. Las mismas ayudaron a esclarecer algunos puntos de apoyo sobre los que se sustentó el trabajo. La definición de Manipulación fue entendida siguiendo a Romano (2011) como "el empleo deliberado del lenguaje para la confusión de las conciencias y la ocultación de la realidad" (p.7). Asimismo Romano (2012) añade que (...) significa envolver de tal modo la información que desaparezcan las contradicciones"(p.189). Esta definición fue primordial para adentrarnos en la temática. La Manipulación Emocional se inscribe dentro de esta categoría pero tiene como peculiaridad que se utilizan técnicas tendientes a manipular al televidente a través de aspectos sentimentales (música, prosodia, formas, lenguaje no verbal, luminosidad y colores, entre otros) que son analizados a través del hemisferio derecho del cerebro de los mismos -y conocido como el cerebro emocional-. Consideramos que es importante reconocer, siguiendo a García, DÁdamo \& Slavinsky (2011) que "razón y pasión no son antitéticas. Toda la información activa emociones y, cuando razonamos, las ideas se acompañan de emociones" (p.163), sin embargo, de lo que se trata aquí es de preponderancia de un aspecto sobre el otro. En contraposición a la Manipulación se concibe la "Información” que, según Romano (2012) es la “(...) formación, configuración (...) formación como proceso de explicación y aclaración, y como resultado (formación adquirida)" (p. 26). A esto el autor agrega que " (...) la satisfacción de esta necesidad implica la adquisición de conocimientos cada vez más amplios acerca de los complejos procesos sociales" (p.28).

En la investigación se estudiaron diferentes definiciones de medios de comunicación creadas a lo largo de la historia. Las definiciones, sin embargo, centran la atención en el aspecto relacional; en base a la relación de oposición de unos con otros. Es el caso de medios que se definen siguiendo al comunista italiano Antonio Gramsci (1972) como hegemónicos Vs contra-hegemónicos en base a la caracterización realizada en su libro "Cartas desde la Cárcel". También se los clasifica como medios "alternativos" Vs "Tradicionales" o "Imperialistas" Vs "Antiimperialistas". Estas no implican necesariamente una definición con respecto a la función específica del medio en sí sino a algunos posicionamientos aislados que puede adoptar. Esto genera una dependencia de unos medios en relación con otros a tal punto que sin la existencia de estos últimos dejaría de tener sentido la denominación misma de los primeros (no puede haber medios alternativos o contra-hegemónicos sino en relación a otro tradicionales o hegemónicos). En estos momentos se hace necesario ir más allá, ir por más, y establecer definiciones que no tengan que depender de las definiciones de los sectores o ideologías opositoras.

Es por esto que en la investigación se generaron nuevas categorías para denominar a los medios en base a su función en sí, independientemente del aspecto relacional. En este sentido se consideró como "medios de comunicación sometedores" (o medios de comunicación para el sometimiento) a aquellos que buscandesinformargenerandofalsasrepresentaciones con la finalidad de someter a la población mediante la 
reducción y tergiversar de sus procesos cognitivos, lo que acota paulatinamente sus niveles de conciencia y de libertad. De esta forma se puede someter a la población objetivo mediante engaños premeditados. Estos "Medios de comunicación sometedores" pueden responder a diferentes intereses como por ejemplo los imperialistas y, por lo tanto, se constituyen en medios de comunicación sometedores de carácter pro-imperialistas. Otros, sin embargo, se pueden constituir en "sometedores" y a la vez ser, por ejemplo, "antiimperialistas".

A diferencia de esta definición se considerará como "Medios libertarios" (o "para la liberación") a aquellos que buscan informar a las poblaciones, de modo veraz y oportuno, para que puedan adquirir conocimientos cada vez más amplios sobre la economía, cultural, política, los procesos sociales en su conjunto, entre otros $\mathrm{y}$, de este modo, posibilitar la generación de procesos cognitivos ascendentes que aumenten su grado de libertad. La información supone, por lo tanto, una ampliación de la conciencia.

Esta relación se establece porque según Romano (2012) puede afirmarse "que el grado de conciencia y el conocimiento de la realidad entorno están inseparablemente unidos"(p.29). Como se podrá apreciar, se puede definir a los medios de comunicación en "sometedores" o "libertarios" por su accionar diario y no por la relación de unos con otros. Ambas definiciones son tipos ideales por lo que los medios de comunicación pueden aspirar a llegar a ser de uno u otro tipo como una meta o utopía pero, como toda utopía es inalcanzable, sirve para impulsar, marcar un rumbo, incentivarnos a caminar, pero cuanto más uno se acerca a ella, ella más se aleja.

\section{MATERIALES Y MÉTODOS}

La investigación adoptó la epistemología cualitativa que asume el carácter reflexivo de las investigaciones sociales entendiendo, por tanto, que la "pureza de la precisión" y los controles no son importantes siendo el factor de la constante creación lo que dota, a este diseño, de una profunda riqueza. Las opiniones y comentarios que surgieron de discusiones, charlas, entrevistas, situaciones observadas, impresiones y prácticas sociales que se revelan por medio de los significados, creencias, acciones sociales, símbolos, saberes, entre otros, han sido convertidas en fuentes de conocimiento a través de procesos de interpretación y comprensión que se basa en la intersubjetividad y el consenso como elementos legitimantes. Por esto mismo el diseño cualitativo se denominado emergente y el investigador adopta ineludiblemente una actitud crítica frente a los diferentes planteamientos y propuestas positivistas.

El Paradigma Construccionista Social fue el considerado como más acertado para llevar a cabo la investigación. Éste retoma aportes del constructivismo, la psicología social y el constructivismo social pero constituye un avance en el sentido de que reconoce la función primaria del lenguaje como organizador de las sociedades, como constructor de los mundos humanos contextualizados. En este sentido rompe las limitaciones del constructivismo que toma al lenguaje como mero transmisor de mensajes de un lugar a otro. Asimismo Barnett (citado por Rodríguez, 2008) entiende que la comunicación es resultado del “(...) proceso social primario, es decir, [que] vivimos inmersos en actividades sociales, donde el lenguaje forma parte de esas actividades, de tal forma que impregna la totalidad de la actividad social" (p.82). Este proceso social se basa en negociaciones e imposiciones de diferentes grupos, y sectores de las sociedades. En este "juego" de poder de unos grupos sobre otros -en los que se busca la naturalización de un determinado orden social construido a su vez 
socialmente- desempeñan un rol importante, como instrumentos de socialización y como constructores de identidades, los medios de comunicación. Es a través de los mismos que las relaciones de poder entre los grupos hegemónicos y grupos subalternos, según Losacco (2009) "(...) quedan invisibilizadas a través de mecanismos semióticos que hacen pensar a los de abajo como los de arriba y de allí su extraordinaria eficacia" (p.129).

En los países que se seleccionaron, los estudios que existen en el área mediática audiovisual son pocos y es por esto que la investigación fue de tipo Exploratoria. Se seleccionaron las transmisiones de los noticieros estelares mencionados del día 14 de Febrero de 2013 realizando, además una calificación o listado de los temas tratados a lo largo de 18 horas corridas desde las 6 de la mañana hasta las 12 de la noche del mismo día. En relación a las técnicas de investigación se utilizó el "análisis de contenido" y "análisis documental". Asimismo se contó con instrumentos, como por ejemplo el cuaderno de campo, grabador, guía de entrevista, libreta de notas, entre otros.

\section{El Deconstruccionismo Sensorial}

La búsqueda de generación de nuevos conocimientos, dentro del área de los medios audiovisuales $\mathrm{y}$, específicamente, dentro del estudio de las técnicas de manipulación llevadas a cabo mediante estímulos emocionales, llevó a la necesidad de buscar nuevos caminos para llegar a nuevos destinos. Fue por eso necesario realizar una nueva metodología que denominamos "Deconstruccionismo Sensorial". El término deriva del concepto de Deconstrucción que siguiendo la definición de la Real Academia Española (2001) consideramos como desmontar un concepto o de una construcción intelectual, o en este caso un conjunto de percepciones, por medio de su análisis mostrando así contradicción o ambigüedad e incoherencias. Asimismo, adoptamos el concepto de Deconstruir de la Real Academia Española
(2001) entendido como deshacer analíticamente los elementos que componen una estructura conceptual. Con respecto al aspecto sensorial se consideró en el sentido de hacer referencia a los sentidos que son estimulados al audio-visualizar un programa determinado.

La metodología fue definida como la separación de los estímulos sensoriales en sus partes constituyentes para la realización de un estudio centralizado y, a continuación, reunificarlas y establecer una interpretación holística. En este sentido según el Diccionario Larousse (1999) Sensorial es "el adjetivo relativo a las sensaciones en tanto que son fenómenos sicofísicos" (p.913). Asimismo, el mencionado diccionario establece que la sensación es la "información recibida por el sistema nervioso central cuando uno de los órganos de los sentidos reacciona ante un estímulo externo" (p.913).

Para la aplicación de la metodología se creó un cuadro en el cual se procedió a la separación vertical en dos columnas para establecer las características denotativas y connotativas. En este sentido acordamos con Pere Marqués (2000) quien considera como denotativo a lo que significa una palabra o muestra literalmente una imagen, es decir, lo que se percibe sin hacer valoraciones. Por otra parte, nos basamos en Apriles (2006) quien define como mensajes connotativos a aquellos que "Traen a colación significaciones e imágenes que estén latentes en los receptores" (p.22).

Por ser medios audio-visuales, la manipulación se realiza a través de la estimulación, en diferentes grados, de ambos sentidos. Sin embargo, no solamente se puede dar esto generando estímulos por separado sino también por una combinación en ambos sentidos a la vez. La estimulación de uno de ellos con imágenes agresivas pueden ser utilizadas con una música asincrónica que se use como contrapunteo (por ejemplo: música alegre acompañando de 
imágenes violentas) $\mathrm{y}$, de este modo, de una tesis (pacífica auditiva) y una antítesis (agresiva visual) se puede generar una síntesis manipuladora que tiene mayor impacto en el televidente que la suma de sus partes por separado. A continuación se procedió a realizar una división de cuadro horizontalmente entre los aspectos centrales que presenta cualquier medio audiovisual como son los que tiene que ver con lo auditivo (que denominamos audio) y los que tienen que ver con lo visual.

Para poder identificar a cada segmento se los nombró (en el lateral izquierdo) con el titular que el noticiero eligió para la noticia. En caso de que la noticia no hubiese presentado un titular escrito se creó uno en base a lo mencionado por el Ancla o periodista (según fuese el caso). Estos titulares tuvieron la función de ser punto de guía para realizar la interpretación de los mensajes que se buscaron enviar a los televidentes. Junto con la denominación del segmento noticioso se marcó el punto de inicio de la noticia y la duración; esto permitió generar estadísticas relacionadas con la duración de cada tipo de noticia, el tiempo de noticias emocionales y racionales que hay en el noticiero, entre otros.

Asimismo se establecieron "separadores" horizontales, en los casos pertinentes, que sirvieron de orientadores. Algunos de separadores que podemos mencionar se encuentran los siguientes: Inicio del noticiero, Síntesis de noticias, Presentación del noticiero, Desarrollo de noticias, Internacionales, Deportes, Fin del noticiero, entre otros. Esta misma separación se ha realizado para dividir el noticiero de los "Espacios Publicitarios" que se presentan a lo largo del horario del noticiero.

Dentro de cada casilla del cuadro, se diferenciaron especificidades a tener en cuenta. Para las noticias que cuentan con soporte audiovisual (sin un periodista que sea enfocado) y "palabras en of" que relatan lo que se muestra, se estableció la subcategoría "Soporte Audiovisual". Por otro lado, para los soportes audiovisuales que muestran al periodista que realiza la noticia - y por lo tanto con voces que no solamente aparecen en of- se determinó crear la subcategoría "Periodista con Soporte Audiovisual". Finalmente se estableció la subcategoría "Soporte Visual" para aquel soporte que sólo mostró imágenes (no presenta voz en of ni a un periodista que desarrolle la noticia).

Esta división en subcategorías, dentro de las casillas del cuadro, permite mantener la estructura semi-estructurada del mismo que es ideal para las investigaciones cualitativas y, en especial, para la que se desarrolló en este trabajo. Además permite llegar al lector desde un aspecto visual utilizando herramientas que van más allá de la mera lectura, generando estímulos visuales diversos y acercando, el escrito en papel, a la fuente audiovisual que se caracteriza por su multidimensionalidad.

De este modo el cuadro contiene cuatro casillas centrales:

- Visual Denotativo: Dentro de esta casilla se trataron las siguientes categorías y subcategorías según sea el caso: Imágenes, Colores, lluminación, Textos y grafico (donde se transcribe lo que se puede leer en la pantalla), Forma de titulares, Color de titulares

- Visual Connotativo: En esta categoría se realizó la interpretación Connotativo (implícito) de lo que cada aspecto visual connotativa buscó generar en el espectador. Para esto se interpretaron los principales lenguajes no verbales, de las personas que se muestran en las diferentes tomas de cada segmento cuando los mismos fueron significativos (buscaron generar un estímulo en el espectador). Asimismo, se realizaron interpretaciones de los efectos o estímulos que el noticiero buscó generar en el televidente y para los cuales determinó mostrar un tipo de iluminación, escenario, color, formato de titular, planos de cámaras y cantidades de tomas específicas -y no otro-. Además se tomó en cuenta el tipo de mensaje connotativo que el 
noticiero buscó enviar al televidente a lo largo del segmento.

- Audio Denotativo: Dentro de esta compartimiento se trataron las siguientes categorías y subcategorías según fue el caso: Palabras (de presentadores, periodistas, entrevistados, etc.), Música, Ruidos, Silencios.

- Audio Connotativo: Dentro de esta casilla se interpretó la prosodia de las personas que hablaban, el tipo de música, y todo lo que relacionado con la generación de mensajes connotativo/subliminales a través de lo auditivo. En este sentido se estableció, cuando fue necesario, la explicación del tipo de discurso que el noticiero/ periodista armó a lo largo de la nota.

Este formato fue aplicado a cada segmento de cada noticiero por separado y logró el objetivo esperado; simplificar la información sin por ello generar una disminución en la profundidad de las interpretaciones. A pesar de la división del cuadro, fue necesario pensar en la necesidad de separar también la percepción sensorial física a la hora de realizar la investigación para lograr una comprensión mucho más profunda evitando que el investigador sea manipulado $y$, al mismo tiempo, pueda experimentar las influencias por separado que desde los noticieros se generaron.

Es por esto que, para poder interpretar ambos aspectos, se audio-visualizó la transmisión televisiva de los noticieros anteriormente mencionados. A continuación se procedió a anular la utilización de un sentido para centrar la atención o priorizar el otro. Para esto se eliminó el estímulo auditivo de la programación mediante la anulación del audio (aunque también se puede utilizar tapones para oídos) para aumentar la concentración de la atención en el aspecto visual. Luego se completó la cuadrícula Visual-Denotativa. Seguidamente se realizó lo contrario; se procedió a eliminar el estímulo visual para aumentar la atención en el sentido auditivo. Dentro del aspecto auditivo, se realizó un segundo esfuerzo al centrar la atención en el aspecto denotativo del mismo sin tener en cuenta la prosodia. A continuación se completó la cuadrícula Auditiva denotativa.

Seguidamente se procedió a interpretar lo escrito en el cuadro Denotativo Visual para establecer los aspectos connotativos y completar la cuadrícula Visual-Connotativa. Finalmente se realizó un trabajo semejante con el aspecto Audio- Connotativo realizando la interpretación de los significados latentes de la cuadrícula Audio-Denotativa y, en particular de la prosodia. Esta novedosa metodología permitió eliminar el desvío de la atención que, desde los medios audiovisuales, se utilizó como herramienta para llevar a cabo las manipulaciones. La aplicación de la misma posibilitó dilucidar, con mayor precisión, los significados connotativos que se escondían detrás de los significados denotativos. De este modo se logró poner luz sobre los mensajes subliminales para hacer que, lo que estaba latente, se convierta en evidente. Una vez realizada esta "metamorfosis", se procedió a llenar la columna connotativa.

La metodología que se creó en esta investigación puede ser utilizada en un futuro por otros trabajos que se desarrollen en el ámbito de medios audiovisuales o en aquellos donde se generen estímulos para más de un sentido a la vez. Asimismo puede ser utilizada para unidades de investigación más grandes o más chicas como pueden ser varios programas de un canal (sin separación por segmentos) o de tomas y planos -que duran en muchos casos menos de un segundo-. La cantidad de categorías que pueden interpretarse pueden variar añadiendo algunas -como las características físicas de los periodistas, el tamaño de las escenografías, la cantidad de tomas de las cámaras, etcétera- y/o sustrayendo otras.

Una vez completado el cuadro mencionado, el conocimientodelinvestigadordeloquesucedíasegundo a segundo en cada segmento de los cuatro noticieros fue completo. En base a este se desarrollaron cuadros 
secundarios con divisiones en base a los segmentos y a las estadísticas sobre los aspectos racionales y emocionales. Asimismo se realizaron otros sobre el tipo de noticia que se transmitió en cada segmento -clasificándolas en políticas, espectáculos, policiales, economía tecnología, deportes, internacionales y otros-. El Deconstruccionismo sensorial, por lo tanto, toma en cuenta aspectos diversos que en otras metodologías son ignorados o menospreciados. La multidimensionalidad de los medios de comunicación audiovisuales puede ser plasmada cabalmente en esta metodología.

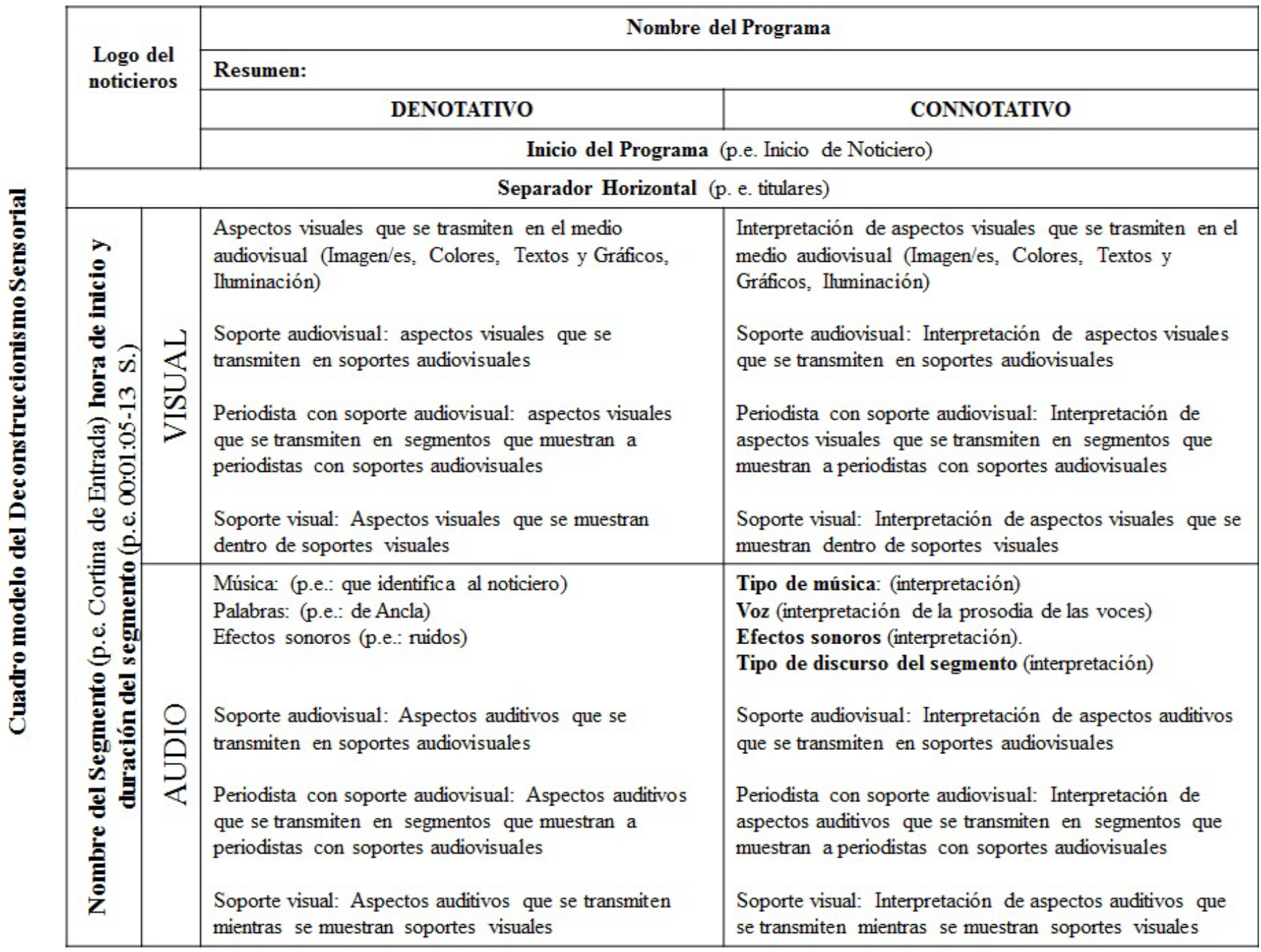

Figura $\mathbf{N}^{\circ}$ 1: Cuadro modelo del deconstruccionismo sensorial 


\section{RESULTADOS Y DISCUSIÓN}

Los medios de comunicación, al ser centros de difusión de ideologías, cuentan con planteles de psicólogos, sociólogos, psiquiatras, antropólogos, comunicadores sociales y politólogos -entre otros- que trabajan en conjunto, desde sus diferentes profesiones, para conformar (como en un laboratorio) determinados mensajes que logren efectos en el público objetivo. En el caso de la televisión, los televidentes son vistos muchas veces como ratas de laboratorios y, mediante diferentes estímulos se busca generar determinadas reacciones (La relación causa efecto, sin embargo, no es lineal pues entran en juego factores sociales, culturales, vivencias, roles, ideologías, etcétera, de los espectadores).

En tanto noticieros estelares, cada uno de los analizados, contienen la esencia política más importante de toda la programación diaria del canal en el cual realizan sus respectivas transmisiones. Utilizando diferentes tácticas, algunos dejan entrever su lineamiento político más directamente que otros. Casos como el de "Visión Siete Central" buscaron mostrar, en determinados segmentos, posturas de entrevistados que son contrarias a las del gobierno. A esto se suma que en este noticiero se pudo notar que los periodistas tienen un grado importante de independencia. Di Guglielmo (2010) considera que los periodistas que cuentan con esta independencia "logran mantener un buen equilibrio no solo cuando informan sino también cuando opinan" (p.101). Otros noticieros, como "Telenoche", "La Noticia Emisión Estelar" y "Noticias Globovisión" sólo transmitieron noticias acordes a los intereses políticos, económicos y sociales que defendieron. No existe un solo segmento donde algún entrevistado o periodista haya transmitido posturas antagónicas a las de sus líneas editoriales. Las escasas que se transmitieron fueron descontextualizadas para dar lugar a análisis de lo más disparatados.
Los discursos y conceptos que se utilizaron en unos y otros noticieros marcaron cabalmente algunos lineamientos políticos de cada uno. Para darun ejemplo, los noticieros estelares de Argentina centraron el eje más evidente de la discusión ideológica en el aspecto punitivo de la policía. Mientras el noticiero opositor transmitió noticias en las cuales se buscó demostrar la necesidad de aplicar mayor "mano dura" incluso en precintos carcelarios (donde los condenados ya cumplen condena), el noticiero gubernamental "Visión Siete Central" mostró noticias relacionadas con la desaparición forzada de un menor a manos de la policía bonaerense para buscar hacer hincapié, por lo tanto, en las consecuencias del exceso de la aplicación de "mano dura" y la necesidad de mayor control hacia la policía.

A diferencia de los noticieros Argentinos, los noticieros Venezolanos hicieron eje en aspectos económicos relacionados con la devaluación de la moneda venezolana a principio de 2013; mientras el noticiero "La noticia Emisión Estelar" del canal gubernamental VTV habló de un "ajuste cambiario" para referirse a la misma, el canal opositor, a través del noticiero Noticias Globovisión, habló de "Paquetazo Rojo" y "devaluación económica". Asimismo, se observó una disputa entre dos formas de ver el aspecto de la seguridad: el noticiero opositor transmitió noticias de asesinatos y represión -o violación de derechos humanos- por parte del gobierno en seis segmentos mientras que el noticiero gubernamental utilizó cinco segmentos para demostrar que crecieron los índices de seguridad y que la corrupción se encontraban en las filas opositoras. De este modo, la culpa de los males fueron lanzados de un lado hacia el otro sin demostrar debilidades o errores en el accionar del gobierno -en el caso del noticiero gubernamental- o fortalezas de este -en el caso del noticiero opositor-.

La argumentación, sin embargo, prevalece del lado gubernamental siendo "Noticias Globovisión" quien utiliza mayores aspectos emocionales no racionales. 
En este sentido, aunque la racionalidad puede buscar manipular al televidente recurriendo a esconder, o no mencionar, aspectos claves que podrían ser centrales para una mayor comprensión de los hechos por parte del televidente, los estímulos emocionales tienen como corolario que, al ser utilizados, dificultan -en mayor proporción que las explicaciones racionales- la apreciación de contradicciones en los discursos.

En este sentido, es interesante mencionar que una importante división que se debe hacer entre las formas de comunicación política.

No es lo mismo una comunicación política honesta o intencionalmente sesgada, constructiva o destructiva, esperanzadora o manipuladora de miedo. No es lo mismo proponer que todos los conceptos admiten controversia y debate, que realizar una operación cognitiva para intentar introducir una idea como la única "normal" en la corriente del discurso político. No es lo mismo utilizar un marco conceptual que otro, ni unas palabras u otras al definir un problema y estimular la cosmovisión y el pensamiento público acerca de él, sus causas y sus derivaciones. Tan importante como decidir "que" comunicar, es tomar la decisión de "como" comunicarlo y encuadrar lo que se comunica. En todos los casos, debemos ser conscientes de que esa elección y esa decisión tendrán, siempre, profundas implicancias y consecuencias en la calidad del debate público. (García, DÁdamo \& Slavinsky, 2011, p.164)

Por lo tanto, aquellos noticieros que llamen a la reflexión, al debate, a una comunicación honesta, y admitan el carácter multidimensional que atraviesa la totalidad de los aspectos políticos, económicos, sociales, culturales, etcétera dentro de las sociedades, se constituirán en medios libertarios fortalecedores de los procesos cognitivos, los demás -aquellos que busquen la linealidad la manipulación y el ostracismo- serán medios sometedores más allá de que se autodenominen como quieran hacerlo (revolucionarios, imperialistas, neutrales, apolíticos, populares, entre otros).

Una característica central que se observó en el noticiero opositor Telenoche de la Argentina es que, transmitió gran cantidad de segmentos en los que no se dio ninguna información noticiosa de relevancia para el quehacer regional o nacional. Noticias relacionadas con farándula, entretenimiento banal y humor fueron transmitidas durante decenas de minutos sin pensar en reparos éticos con respecto necesario rol de los noticieros como supuestas "herramientas de información de la población".

La teatralización como técnica de manipulación emocional también fue considerada en la investigación. La utilización de la dramatización y teatralización en los noticieros no debe ser considerado una cuestión menor. El lenguaje no verbal y los tonos de voz (prosodia) de las personas que fueron televisadas a lo largo del desarrollo de los noticieros fueron centrales pues, son estas técnicas algunas de las que se utilizan para influencian y predisponer, desde aspectos sentimentales, a los televidentes según los intereses del noticiero. Esta dramatización no se dieron solamente en el caso de los periodistas sino -y principalmente- en los anclas. Telenoche cuenta con dos Anclas, un hombre y una mujer. La teatralización de ambos Anclas es constante. Utilizan rutinas premeditadas en las que la improvisación es mínima. En el caso de este noticiero, la presentación de las noticias se intercalaron siendo presentadas una vez por el Ancla (Santos) y otra por la ancla (María).

Dentro de esta rutina se destacó la similitud con la conocida puesta en escena de "la policía buena y el policía malo". Al hablar, María (la policía buena) realizó una rutina teatral que se centró en mostrarse como ingenua y hablar como si se estuviera dirigiendo a niños. Aharonian (2007) establece que esta transmisión de noticias de "la misma forma en que 
uno le habla a los niños: sencilla, brevemente y de forma emocional, [conduce] inevitablemente, a una concepción reduccionista del pensamiento"(p.20). En este sentido el estímulo que produce esta forma de comunicarse tiene por función una respuesta de las mismas características por parte del televidente; se buscó que éste último se sitúe en el rol de un niño o una persona infradotada u oligofrénica. Por otro lado, cuando es el turno de Santos (el policía malo) desarrolló un papel, a través del lenguaje verbal y no verbal, mayormente centrado en el enojo, la indignación, y la impotencia (la prosodia del Ancla acompañó constantemente su lenguaje no verbal). La teatralización del Ancla, buscó que los sentimientos que dramatizó fuesen sentidos por el espectador. Cuando las noticias fueron del gobierno puso caras de enojo, ira e impotencia para que el televidente se predispusiera negativamente ante el gobierno y sus funcionarios.

Los otros noticieros, especialmente "Noticias Globovisión", presentaron también cierto grado de actuación aunque no con tanta frecuencia como en el caso de Telenoche. Los papeles de la Ancla fueron más heterogéneos. Su lenguaje verbal y no verbal cambió de alegre a irónico, serio y de desaprobación. Estos últimos se produjeron cuando se habló del gobierno bolivariano o se presentó una noticia relacionada con el mismo. Aunque no llegó al extremo de hablar como si se estuviera dirigiendo a niños, sí realizó algunos movimientos corporales lentos y de acentuación de lo que estaba diciendo que se acercaron a un lenguaje cercano a hablar con niños. Finalmente, tanto los noticieros "Visión Siete Central" como "La Noticia Emisión Estelar" dieron menor importancia a la utilización del lenguaje no verbal como orientador de significados en el público. Ambos centraron el articulado de sus programaciones en aspectos de mayor racionalidad y argumentación y menor emotividad.
Además de los aspectos teatrales, no verbales y dramatizaciones, fueron centrales en la investigación, la interpretación de la música, los efectos sonoros y los silencios como guías invisibles. Humor, alegría, tristeza, terror, suspenso, emoción, ensueño, serenidad; la música genera sensaciones, emociones y reacciones que van más allá de simples "ambientaciones". Según Pnset (2011) no existe nada que tenga más impacto sobre el cerebro que la música ya que la misma afecta la memoria, afecta las emociones, incluso afecta el movimiento, lo afecta prácticamente todo.

Los efectos que la misma tiene sobre el público son subestimados, no solamente por el común de la población en general, sino por la "academia" que muchas veces la ha considerado como un accesorio de los argumentos y factores racionales. Se consideró innumerables veces que es esta última la que se utiliza en la pantalla de televisión para transmitir ideologías cuando, en realidad, es la música la que influencia y marca el contexto. Es el tablero sobre el que se monta la noticia y que predispone fuertemente al televidente, de manera subliminal, a adoptar una determinada actitud frente a lo que se dice. Los impulsos o incentivos que se activan desde los noticieros, al utilizar este estímulo, no bloquean la capacidad racional del televidente sino que lo influyen, generan las condiciones tendientes a que sea más probable que el espectador interprete de una manera y no de otra lo que está viendo y escuchando.

En este caso, también es "Telenoche" el noticiero que más cantidad de estos recursos utiliza estando el $100 \%$ de sus segmentos atravesados por algún tipo de música. Si de este $100 \%$ realizamos el ejercicio de no tomar en cuenta la música que caracteriza al noticiero -que tiene por finalidad generar familiaridad entre el espectador y el programa (y que es un aspecto en común en todos los noticieros)-, tendremos una cifra de la música que concretamente podría no estar presente y que, sin embargo, se emplea para influenciar y predisponer, a través de manipulación, 
al espectador. La cifra de este tipo en particular de música, en el caso de Telenoche, fue del $91 \%$ quedando sólo el $9 \%$ como música característica del noticiero. A esto se debe añadir que las músicas utilizadas fueron en su mayoría de tipo disonantes (que tienen la finalidad de generar terror y suspenso en la población). El noticiero también utilizó música de tiempos rápidos cuyo fin fue generar emoción y alegría, aunque este tipo se transmitió en menor medida que el primero.

Distinto sucedió con el resto de los noticieros en los cuales la relación entre música del noticiero y música netamente con fines de predisponer al televidente ante las noticias, se invirtió siendo esta última menor que la primera. Telenoche utilizó casi tres veces más música con el fin de manipular al televidente que lo que usó el noticiero del canal gubernamental de Argentina y veinte veces más de lo que usó el noticiero gubernamental de Venezuela. En el noticiero "Visión Siete Central", de los 26 segmentos 21 contenía música y de estos el $66 \%$ fue música característica del noticiero y sólo el $33 \%$ restante fue utilizada para otros fines. Si se toma en cuenta el total de los segmentos, la música que no era característica del noticiero representó el $27 \%$ del total, la característica del noticiero el $53 \%$ y el restante $20 \%$ no contuvo ningún tipo de música. La música mayormente utilizada, a diferencia de Telenoche, no fue disonante sino de tiempos rápidos y tiempos lentos por lo que la finalidad fue completamente distinta; pues se buscó generar sentimientos de serenidad, ensueño, emoción y alegría.

Los aspectos de musicalización para manipular, como se observa en el gráfico, no son tan importantes en los noticieros Venezolanos como sí lo son en los noticieros argentinos.

\section{ESTÍMULOS SONOROS EN LOS NOTICIEROS}

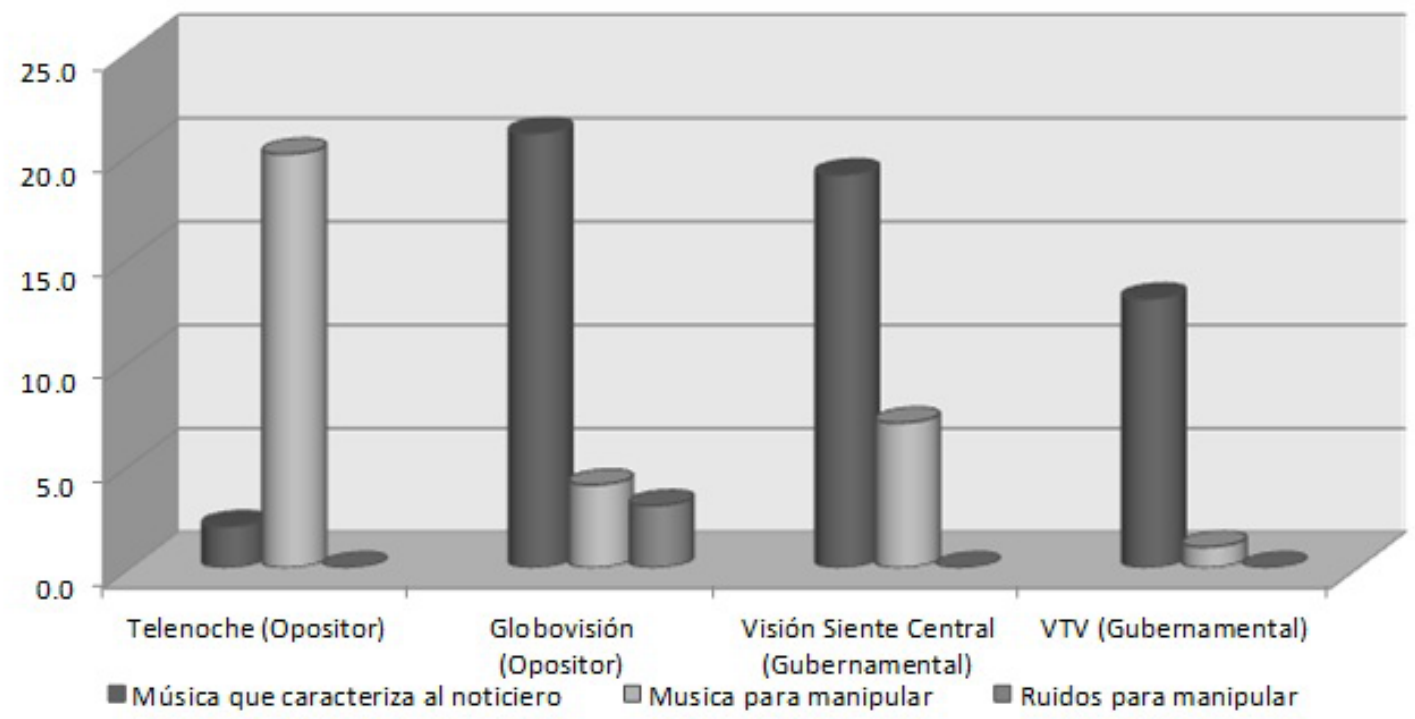

Figura $\mathbf{N}^{\circ}$ 2: Estimulos sonoros en los noticieros 
La teatralización y musicalización, sin embargo, no fueron los únicos aspectos interpretados. Las imágenes, luces, colores y formas de los titulares y gráficos también estuvieron presentes en el trabajo investigativo. Las imágenes también cumplen un rol importante a la hora de manipular emocionalmente. El caso más extremo que se encontró en los noticieros interpretados fue la transmisión de lo que más se puede asemejar a un "asesinato en vivo". En "Telenoche", se transmitió un segmento denominado "Pistorius mató a su mujer". El mismo, se trató de una noticia sobre un deportista paralímpico llamado Oscar Pistorius quien supuestamente asesinó a su esposa la modelo Reeva Steenkamp. En este segmento una voz en of relata que la modelo fue encontrada con cuatro disparos. En ese preciso momento, la cámara hace cuatro fundidos en negro que duran menos de un segundo. Los fundidos producen la sensación de que finaliza un periodo de tiempo mientras el negro representa la muerte y la oscuridad.

Es decir que, para aumentar el dramatismo y el terror, el noticiero generó la sensación subliminal, mediante manipulaciones emocionales, del asesinato por segunda vez de la modelo para que el televidente lo pueda ver en vivo y en directo. El noticiero convirtió la muerte de la modelo en un espectáculo. El mismo segmentó además transmitió música disonante que aumentó gradualmente de volumen y que tuvo por función aumentar el clima de terror y suspenso de la noticia. Ese segmento representó, quizá, el extremo de la manipulación emocional mediática producida, mediante aspectos visuales, por cualquiera de los noticieros, banalizando incluso la muerte de una persona.

Se hizo, de la muerte de una mujer a manos de su esposo paralímpico (que debería ser una noticia policial), un show televisivo. Para desarrollar todo un despliegue de cinismo, el presentador de tecnología del noticiero finalizó leyendo un twitter de la víctima horas antes de su asesinato y luego comenzó a especular sobre lo que habría pensado la modelo horas antes de su muerte. En este sentido, el periodista expresó “¿Estaría planeando, como dicen, entrar escondida a la casa de Oscar Pistorius? ¿O no, o estaría planeando otra cosa que estaría planeando? ¿O por ahí estaba solamente ilusionada con otro día de los enamorados que no fue lo que ella soñaba?". Finalmente, para terminar de crear el clima de show, el presentador de tecnología llamó a los televidentes a que opinen, retwitteen y hablen del tema en las redes sociales al exclamar "si, y da para esto, da para retwittearlo, da para hablar de eso".

La metamorfosis de los noticieros de herramientas de información en espacios de espectáculo constante llegó, en el caso de Telenoche, a niveles en los cuales las noticias de política, economía, tecnología, deportes, internacionales y policiales fueron relegadas a segundos, terceros, cuartos, quintos y sextos lugares. Este exceso de espectacularización no se produjo, sin embargo, dentro de segmentos delimitados como tales sino que, muchos segmentos que deberían ser presentados como noticias políticas y policiales, fueron presentadas haciendo eje en aquellos aspectos más triviales e irrelevantes pero que, fueron centrales para poder "armar un buen show". Diferente sucedió con el resto de los noticieros en los cuales los segmentos de espectáculos fueron reducidos y bien delimitados dentro de algunos segmentos. Visión Siete Central utilizó este segmento para dar preponderancia a las producciones fílmicas y teatrales nacionales mientras que, Noticias Globovisión, lo utilizó para transmitir su ideología contrarrevolucionaria mediante elipsis y mensajes subliminales. En el caso de "La Noticia Emisión Estelar" del canal gubernamental VTV, el segmento de farándula ni siquiera existió. 


\section{DISTRIBUCIÓN POR TEMAS DE LOS NOTICIEROS}

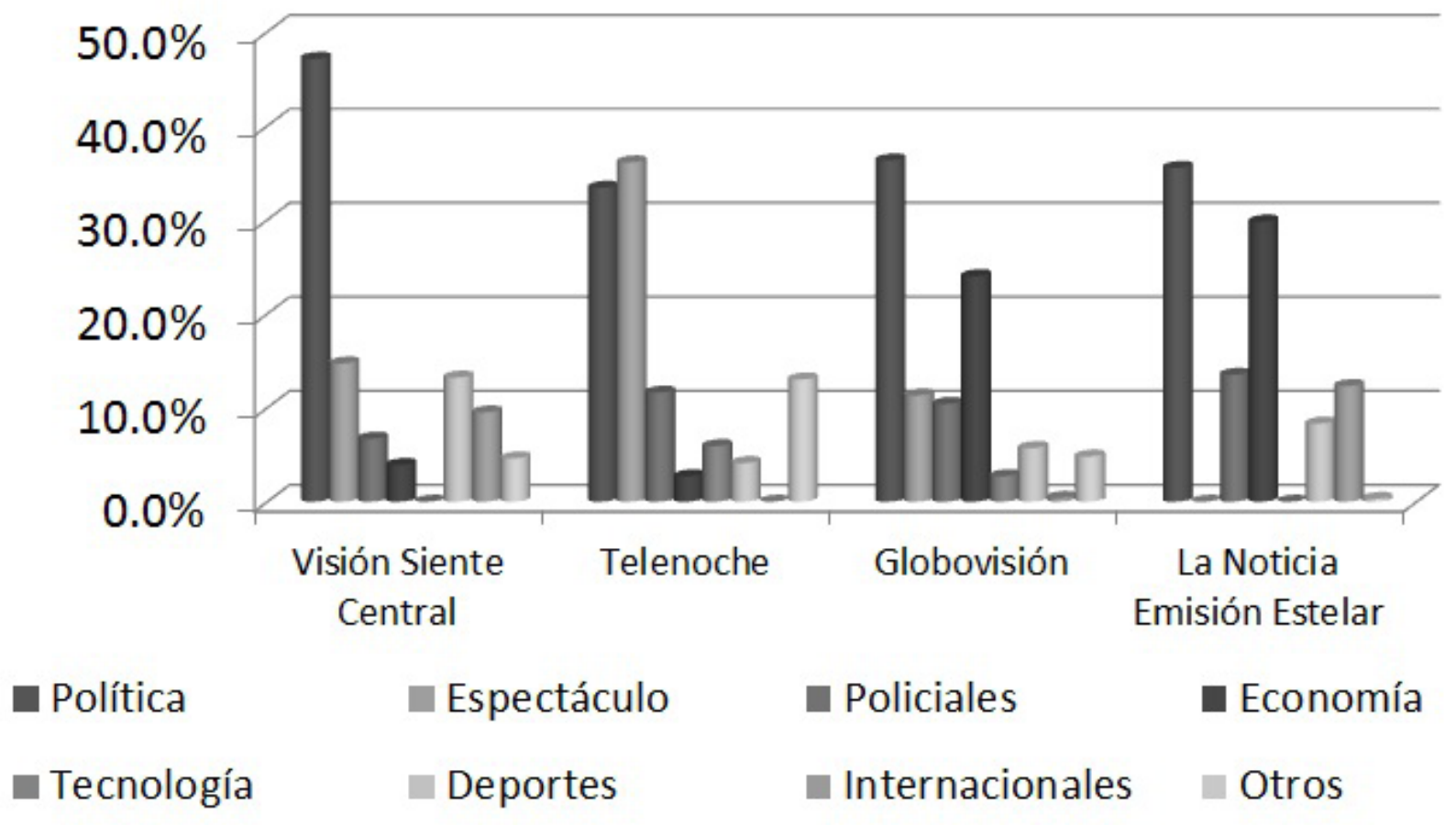

Figura $\mathrm{N}^{\circ}$ 3: Distribución por temas de los noticieros

La transmisión de imágenes cuyo fin fue exclusivamente la manipulación emocional también se apreció en otros segmentos de "Noticias Globovisión" y "Telenoche". En las noticias relacionadas con asesinatos y policiales, ambos noticieros hicieron eje en mostrar la tristeza e impotencia extrema de los familiares y amigos de las personas asesinadas. Estos familiares en tanto víctimas de la delincuencia, fueron utilizados como conejitos de indias por los medios de comunicación. Zaffaroni (2012) explica que la exposición de los parientes y amigos directos de las víctimas a las cámaras y acoso por parte de periodistas siempre “(...) infiriere un grave daño psicológico; lo que se hace con [ellos] es poco menos que una vivisección psíquica" (p.232). En este sentido, la víctima o familiar de la víctima es entrevistada en un momento específico de "extroversión de la culpa" que, según Zaffaroni (2012) "refuerza al máximo esta etapa, inmoviliza a la persona en este momento e interrumpe brutalmente el camino de elaboración del duelo, o sea, de restablecimiento de su equilibrio emocional"(p.233). Los noticieros, sin embargo, no dieron importancia a las consecuencias psicológicas que crearon en las víctimas por sus exposiciones ante las cámaras, sino que, simplemente tomaron esto como "daños colaterales" en una batalla por el aumento del rating en la cual la transmisión del dolor ajeno, suma muchos puntos.

Con respecto a la iluminación empleada en los set centrales, en ambos noticieros estelares de los canales argentinos, los anclas fueron iluminados con luces cenitales. Las misma tuvieron la función de generar la asociación de los Anclas con personas culta, conocedora; Les otorgó legitimidad. De este modo, a través de la iluminación se trabajó sobre las emociones del espectador. La misma, sin embargo, no tuvo tanto efecto si lo comparamos, por ejemplo, con el empleo de diferentes tipos de musicalización o los lenguajes no verbales de los anclas. Por lo tanto, 
en los segmentos donde se evidenció este tipo de iluminación, se tomó más en cuenta la presencia o ausencia de los otros dos aspectos (música y gestos) a la hora de realizar la interpretación para definir el grado de emocionalidad y racionalidad. La iluminación en los noticieros estelares Venezolanos, es diferente, no es cenital sino más diversificada.

Con respecto a los colores, "Telenoche" utilizó gamas de rojos y negros. Los colores oscuros fueron la regla y buscaron generar emociones negativas de tristeza, oscuridad, soledad, muerte y a la vez exaltantes, pasionales y de peligro. El noticiero "Visión Siete Central" (Gubernamental de Argentina), en contraposición, utilizó gamas de colores celestes y blancos que buscaron generar sensaciones de paz, armonía lealtad, dignidad, confianza, en fin: emociones positivas. La disputa emocional del televidente, se produjo, por lo tanto, también a través de los colores que fueron transmitidos en ambos noticieros.

Los noticieros venezolanos, por otro lado, presentaron disparidades. El noticiero opositor utilizó, al igual que en el opositor argentino, el color negro como predominante en la búsqueda de generar los mismos fines emocionales que los de Telenoche. El noticiero gubernamental de Venezuela, en contraposición, no hizo hincapié en este aspecto. Los colores que se transmitieron fueron oscuros y claros transmitiendo sensaciones contradictorias al espectador. Los resultados de las diferentes técnicas de manipulación emocional fueron plasmados en un cuadro estadístico que sirvió para poder percibir, visualmente y de manera más acabada, las grandes diferencias que se presentan entre las construcciones de cada uno de los noticieros. Las diferencias, de esta manera, se hicieron palpables y facilitaron la comparación entre los cuatro programas noticiosos. En base a esto se pudieron realizar ciertos avances interpretativos que mostraron patrones significativos.
El noticiero "Telenoche" resultó ser el programa que más utilizó técnicas de manipulación emocional con un $89,6 \%$ de presencia de las mismas mientras que sólo un 10,4\% fueron noticias presentadas de manera racional fomentando una visión crítica del televidente. Esto significa que las técnicas de emocionalidad se utilizaron casi ocho veces más que las racionales. Estadísticas, muy altas en cuanto al grado de técnicas de manipulación emocional, también presentó "Noticias Globovisión" con dígitos que superaron el $73 \%$ mientras que las noticias presentadas desde aspectos racionales no llegaron al $27 \%$. En este noticiero, la relación fue de casi 3 a 1 a favor de la emocionalidad.

Un cambio radical se produjo en los noticieros "Visión Siete Central" y "La noticia Emisión Central". En el caso del primero, la cifra de racionalidad llegó hasta el $60,6 \%$ superando con creces a la de emocionalidad que se posicionó en un $39,4 \%$. De este modo la relación fue de 3 a 2 a favor de la racionalidad y en detrimento de las técnicas de emocionalidad. El noticiero gubernamental de la República Bolivariana de Venezuela, sin embargo, superó estas cifras posicionando los niveles de racionalidad en un $82,8 \%$ y los de emocionalidad en un $17,2 \%$. Esto dio como resultado un empleo de presentación de noticias en formatos racionales mayor a cuatro veces por encima de las emocionales.

Los Noticieros opositores, de este modo, resultaron utilizar, en promedio, técnicas de manipulación emocionales durante el $81 \%$ de la programación. Las mismas tendieron a disminuir la generación de procesos racionales críticos por parte de los televidentes. Las emociones que buscaron crear en el espectador fueron, en su mayoría, relacionadas con sentimientos de ira, enojo, impotencia y tristeza. En contraposición, los canales gubernamentales emplearon el reducido número de $28.3 \%$ de segmentos con contenido emocional siendo el $71,7 \%$ restante espacios para la reflexión racional y crítica de 
la información que se presentó apoyada en hechos, estadísticas, o ideas económicas.

En el aspecto musical, aunque "Visión Siete Central" presentó más segmentos con estos estímulos que "Noticias Globovisión", este último noticiero terminó posicionándose por encima del noticiero gubernamental por la utilización de otras técnicas emocionales entre las que se encontraron la dramatización o teatralización, los lenguajes no verbales, la prosodia y las imágenes con mensajes subliminales. Dentro de la emocionalidad que se emitió en los canales gubernamentales, un porcentaje significativo se dio por la transmisión de personas que gestualmente demostraron emocionalidad (cuyos gestos no fueron neutrales).

\section{MANIPULACIÓN POR ESTÍMULOS EMOCIONALES Vs ARGUMENTACIÓNRACIONAL}

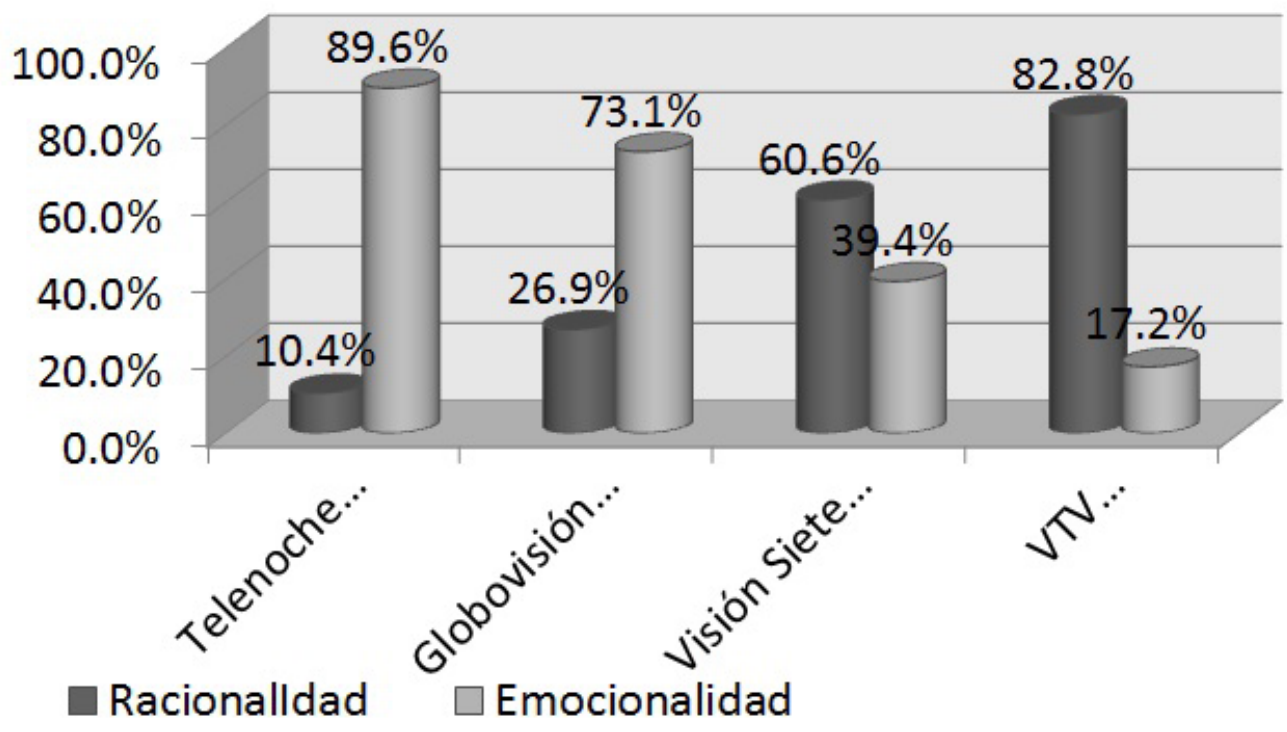

Figura $\mathrm{N}^{\circ}$ 4: Manipulación por estímulos emocionales vs argumentación racional

Frente a la manipulación emocional observada en los noticieros es necesario traer a colación que los pueblos pensantes, razonantes, conscientes siempre han sido más difíciles de manipular y dominar. Cualquier revolución que se quiera denominar popular debe ineludiblemente llevar a cabo una intensa revolución cultural capaz de aumentar cada vez más los niveles de consciencia y la politización de sus habitantes para poder mantenerse en el tiempo traspasando las fronteras personalistas. Esta meta es la más importante y, a la vez, más difícil de lograr pues implica, muchas veces, un cambio rotundo en los hábitos, costumbres e instituciones históricas que se construyeron para dominar a las poblaciones objetivos. Los noticieros opositores centraron su atención en obstaculizar esta meta en particular fortaleciendo la alienación, la falta de valores, de códigos sociales, premiando la bufonada, la banalidad y ridiculizando a cualquiera quienes buscan rescatar determinados valores éticos principalmente los relacionados con la solidaridad.

\section{CONCLUSIONES}

La utilización delaMetodologíadel Deconstruccionismo Sensorial posibilitó interpretar los aspectos denotativos y connotativos tanto en el espectro visual como en el auditivo. De este modo se logró una comprensión detallada de los noticieros segmento por segmentos y a lo largo de los distintos segundos de la programación. La metodología viabilizó la opción de 
evitar la recepción de estímulos emocionales múltiples al mismo tiempo por parte del investigador y, de este modo, las manipulaciones fueron interpretadas por separado sin caer en sus trampas. Los noticieros estelares de los canales de televisión seleccionados enseñan sobre la existencia de una constante pugna de poder y de visiones contrapuestas en las cuales se busca debilitar las ideologías contrarias mientras se fortalecen las propias dentro de un "kung fu" político.

Aunque pueden estimularse emociones positivas como el amor, la felicidad, la paz, la armonía y la relajación también se pueden estimular las negativas como el odio, la impotencia, la desesperanza, el temor, la incertidumbre, entre otros. Estos sentimientos, al multiplicarse por millones de espectadores, generan estados de opinión que pueden ser favorables o perjudiciales para los gobiernos que encarnan determinadas ideologías. Los cuatro noticieros interpretados tuvieron la particularidad de influenciar sobre determinados sentimientos del público.

Los noticieros opositores buscaron la formación de oligofrenia social abocada al consumismo de superficialidades. Para lograr aumentar este fenómeno social, se alentó la espectacularización de los espacios noticiosos y se inyectaron dosis constantes de crímenes, asesinatos, violaciones, torturas y robos que buscaron transformarse en miedo, terror y desesperanza en el público al que se le impuso dicha programación. Asimismo, el entretenimiento, en vez de ser un fin, se transformó en un medio de manipulación emocional constante que mantuvo "distraído" al público mientras se le transmitió determinadas ideologías. Se utilizó el dolor de las víctimas como forma de aumentar los niveles de encendido (o rating) sobre la base de artimañas que gravitaron alrededor del fomento de los aspectos más aberrados, sádicos, morbosos y cínicos del ser humano. Además se crearon "héroes y villanos", siendo los gobiernos los englobados dentro de esta última categoría, para, de este modo, reducir los aspectos multidimensionales de los hechos planteando simplificados escenarios maniqueos.

Noticieros como Telenoche llegaron al extremo de crear lo que emocionalmente se asocia a un "asesinatos en vivo". Los periodistas de este noticiero también realizaron llamados a la población para que especulase con las causas de la muerte de las víctimas transformando un asesinato real en un "reality show". El noticiero se convirtió, de un espacio que debería ser de reflexión y crítica, en un espacio de esparcimiento y pereza mental ideal para dejarse llevar por la ideología que el ancla o el periodista insuflaron sutilmente.

Noticieros como Telenoche dedicaron cerca del $90 \%$ de su programación a generar este tipo de estímulos tendientes al entretenimiento como un medio de manipular emocionalmente al público generando sentimientos de ira, inseguridad, incertidumbre, miedo y desconsuelo. La música disonante, en este sentido, cumplió un rol central a la hora de generar terror en los televidentes. Otros programas como "Noticias Globovisión", llegaron también a la impresionante cifra de casi $3 / 4$ partes de la transmisión con la misma finalidad. Los Anclas/actores, de estos canales mostraron sus gestos más extremos de indignación o enojo para buscar la generación del veneno de la ira por parte del televidente. Los medios de comunicación opositores buscaron, además, generar sentimientos mayormente negativos que fueron canalizados contra la Revolución Bolivariana venezolana y el kirchnerismo argentino. De este modo, la manipulación en ambos casos buscó deslegitimar y debilitar el apoyo de la población hacia ambos gobiernos. Los intereses ocultos detrás de cada noticiero salieron a la luz tanto por los mensajes literales o aspectos denotativos como por los mensajes subliminales, latentes o aspectos connotativos.

El caso del noticiero gubernamental argentino "Visión Siete Central" adoptó una postura intermedia, 
no solamente porque los aspectos emocionales se utilizaron en su mayor parte para generar entretenimiento como un fin $(y$ no como una manipulación) sino porque, además, la mayoría de su programación (más del 60\%) se basó en argumentos y razonamientos mostrando los posicionamientos tanto a favor como en contra de distintas tendencias políticas.

En los noticieros de "La Noticia Emisión Estelar" y "Visión Siete Central", que representan las ideologías gubernamentales, la presencia de emociones positivas fueron mayores que las negativas. En los mismos preponderaron las noticias en apoyo a los gobiernos respectivos haciendo énfasis en los logros obtenidos en beneficio de las poblaciones o de "causas justas". Vale mencionar que la argumentación y racionalidad fueron la norma mientras que la utilización de estímulos emocionales se redujo a espacios temporales minoritarios. En el noticiero "Visión Siete Central", la complementación entre colores, música, lenguajes no verbales y teatralización fue coherente con los fines de transmitir alegría y tranquilidad. Esto no sucedió en el gubernamental venezolano donde la contradicción entre estímulos transmitió contradicciones.

La nueva caracterización de los medios en sometedores o libertarios ayudó a identificar a los mismos en base a sus fines y no en base a su relación con otros (aspecto que sucedía con las denominaciones hasta el momento creadas). La información proporcionada por los noticieros "Visión Siete Central" y "La noticia Emisión Estelar" basada en argumentos fortaleció el conocimiento contextual del público posicionándolos como medios de comunicación de tendencia libertaria.

Sin embargo, siempre es necesario continuar fortaleciendo los procesos de pensamientos críticos que son el maná para reforzar las revoluciones populares y procesos de liberación.

Con respecto a los noticieros "Telenoche" y "Noticias Globovisión", la generación de estímulos emocionales para manipular al televidente fue priorizada antes que la transmisión de información basada en argumentos y hechos. Asimismo, algunos de los segmentos basados en argumentaciones y racionalidad utilizaron recortes de declaraciones de funcionarios gubernamentales que fueron descontextualizadas transformando también la noticia en una mentira. Esto los posicionó dentro del espectro de los medios sometedores pues buscaron desinformar y manipular. Persiguieron la disminución de la generación de procesos racionales críticos por parte de los televidentes. Además, las noticias que transmitieron fueron lineales y unidimensionales.

Mientras los estímulos emocionales sean utilizados para crear un clima ameno y de relajación donde se fomente el análisis crítico de las noticias -por parte del televidente- son válidos. No así si son utilizados para manipular y tergiversar la realidad. Los Anclas pueden transmitir alegría o relajación mientras desarrollan las noticias de una manera natural; Diferente es que cambien sus lenguajes no verbales y prosodias como actores de novelas o personas con trastornos bipolares de personalidad. De lo que se trata, en definitiva, es de mostrar las diferentes posturas, al espectador, para que este decida. Obviamente una postura imperará sobre la otra pues no se puede considerar que los medios adoptarán actitudes neutrales pero, si se muestran los posicionamientos a favor y en contra, se darán las herramientas necesarias para que el televidente pueda interpretarlas. La utilización de las emociones reales y contextualmente pertinentes, pueden persuadir al público sin caer en el aspecto negativo que es la manipulación y de esta forma lograr "convencer" (o vencer con el otro) que es lo que se debería buscar.

\section{BIBLIOGRAFÍA}

Aharonian, Aram. (2007). Vernos con Nuestros Propios Ojos, Apuntes Sobre Comunicación y Democracia. Caracas. Edit. El Perro y la Rana. Serie: Comunicación y Sociedad. 
Barnett, P. En Rodríguez Villamil, H. (2008) Del constructivismo al construccionismo: implicaciones educativas. Bogotá: Educación y Desarrollo Social. [Libro en línea] 1 (2). Consultado el 1/06/2013 en www.es.scribd.com/doc/161560589/ Del-Constructivismo-Al-Construccionismo.

Britto García, Luis. (2012). Dictadura Mediática en Venezuela, investigación de unos medios por encima de toda sospecha. República Bolivariana de Venezuela: Correo del Orinoco.

C. Apriles, O. (2006). La publicidad puesta al día. Buenos Aires: La Crujía. ( $2^{\circ}$ Ed.). Colección: Inclusiones.

Di Guglielmo, H. (2010). La programación televisiva en guerra. Buenos Aires: La Crujía

El Pequeño Larousse llustrado (1999). Diccionario Enciclopédico. Agrupación Editorial, S.A.

García Beaudoux, DÁdamo y Slavinsky (2011). Propaganda Gubernamental. Buenos Aires: La Crujía.

Gergen, Lewis e Izurieta (2005). Cambiando la Escucha; comunicación presidencial para ciudadanos indiferentes. Buenos Aires: La Crujía.

Gramsci, A. (1972). Cartas desde la Cárcel. Instituto Gramsci. Madrid: EDICUSA Editorial Cuadernos para el Diálogo S.A. Divulgación universitaria. Serie Bibliografía $\mathrm{N}^{\circ} 82$.

Losacco J. R. (2009). Las caricaturas de Rayma durante el paro-sabotaje petrolero 2002-2003: una mirada antropológica. Caracas: El perro y la Rana; Colección Alfredo Maneiro; Serie Pensamiento Social.

Ministerio del P. P. para la Comunicación e Información (2010). Proyecto nacional Simón Bolívar años 2007-2013.Caracas: Minci. Objetivo VII-I.1. Enfoque

Ministerio del P. P. para la Comunicación e Información (2012). Plan de la Patria Programa de Gobierno bolivariano 2013-2019. Testamento político del comandante Hugo Chávez.

Pere Marqués Graells. (2000). La Alfabetización Audiovisual. Introducción al Lenguaje Audiovisual.
[Libro en Línea] Consultado el 12/07/2013. En www.peremarques.net/alfaaudi.htm\#inicio.

Pnset, E. Redes $N^{\circ}$ 105. "Neurociencia". [Video en Línea]. Consultado el 15 de Julio de 2013. En www.redesparalaciencia.com

Real Academia Española. (2001). Diccionario de la lengua Española. $2^{\circ}$ edición

Romano, V. (2011). La Intoxicación Lingüística, El Uso Perverso de la Lengua. República Bolivariana de Venezuela: Correo del Orinoco.

Romano, V. (2012). La violencia mediática; el secuestro del conocimiento. República Bolivariana de Venezuela: Correo del Orinoco.

Zaffaroni, E. R (2012). La cuestión criminal. Buenos Aires: Planeta $\left(4^{\circ} \mathrm{Ed}\right.$.). 